\title{
Descriptive Study of Pediatric Patients with Ileum Stoma at Inpatient Installation of Dr. Soetomo General Hospital Surabaya
}

\author{
Farihazqa Hafez Mikala1, Alpha Fardah Athiyyah ${ }^{2 \star}$, I Gusti Bagus Adria Hariastawa ${ }^{3}$, I Gusti \\ Made Reza Gunadi Ranuh ${ }^{2}$
}

${ }^{1}$ Faculty of Medicine, Universitas Airlangga, Surabaya, Indonesia.

2Department of Pediatrics, Faculty of Medicine, Universitas Airlangga/Dr. Soetomo General Hospital, Surabaya, Indonesia. ${ }^{3}$ Department of General Surgery, Universitas Airlangga/Dr. Soetomo General Hospital, Surabaya, Indonesia.

\section{A B S T R A C T}

Introduction: lleostomy is needed as an important part of the management of several congenital disorders of the intestine. One of the indication of ileostomy in children is short bowel syndrome, which is caused by intestinal atresia such as ileal atresia and intussusception. lleostomy is a surgery procedure which consists of creating holes on abdominal walls to release stool. The objective of this study was to determine the description of pediatric patients who underwent ileostomy in Dr. Soetomo General Hospital Surabaya.

Methods: This was a retrospective descriptive study on medical records in the Central Medical Record Department of Pediatrics and General Surgery Dr. Soetomo General Hospital Surabaya from January 2017 to December 2018.

Results: There were 26 pediatric patients who underwent ileostomy in Dr. Soetomo General Hospital Surabaya. Samples from male patients consisted of $57.7 \%$, while female patients consisted of $42.3 \%$ with the most common age group was neonates with $57.7 \%$, infants $30.8 \%$, and toddlers $11.5 \%$. There were $30.7 \%$ patients with 2.0 $2.9 \mathrm{~kg}$ body weight, $27 \%$ with $3.0-3.9 \mathrm{~kg}$ body weight, and $42.3 \%$ with more than 4 $\mathrm{kg}$ body weight. The outcome showed that repair was needed, or the patient was discharged with periodic follow-up after ileostomy.

Conclusion: lleostomy was performed mostly in neonates with average weight within normal body mass index (BMI) and the highest incidence of pediatric patient with ileum stoma was in pediatric patients.

\section{* Correspondence: alpha-f-a@fk.unair.ac.id}

JUXTA: Jurnal Ilmiah Mahasiswa Kedokteran Universitas Airlangga

p-ISSN: 1907-3623; e-ISSN: 2684-9453

DOI: 10.20473/juxta.V12I12021.1-5

Open access under Creative Commons Attribution-ShareAlike 4.0 International License (CC-BY-SA)

\section{ARTICLE INFO}

\author{
Article history: \\ Received 5 November 2020 \\ Received in revised form 19 \\ November 2020 \\ Accepted 4 December 2020
}

\section{Keywords:}

Pediatric,

lleostomy,

Indication,

Outcome. 


\section{Introduction}

lleostomy is needed as an important part of the management of several intestinal disorders. lleostomy in children is performed due to congenital disorders such as intestinal atresia, intussusception, and Hirschsprung's disease which cause intestinal obstruction. lleostomy is a type of stoma, in which surgery was performed by creating holes in abdominal walls as a way to release stool. ${ }^{1}$

Atresia can occur anywhere along the gastrointestinal tract and the clinical presentation of atresia can be determined according to the location of atresia. Most cases occur in neonates with abdominal distension and thick emesis within the first 2 days of life. Intestinal atresia is a common cause of intestinal obstruction in neonates. Congenital obstruction can occur completely or partially, intrinsically or extrinsically. In developing countries, this case ranked fourth as the most common cause of intestinal obstruction in neonates, after anorectal malformation, Hirschsprung's disease, and inguinal hernia. ${ }^{2}$

Intestinal obstruction in neonates depends on the location, accompanied by abdominal distension, vomiting, and constipation. Imaging is the only method of diagnosis to detect early and determine the extension of the lesion and the possibility of the organs involved. lleostomy generally occurs when the condition of the intestine or the proximal colon is in an emergency. This may occur due to an intestinal injury that has been around for a long time (prolonged peritonitis or obstruction). Other indication for ileostomy to occur is due to the emergence of bleeding, ischemia, perforation, or sepsis, including neonates who have intestinal perforation due to NEC (Necrotizing Enterocolitis). ${ }^{3}$

The incidence of ileocolic intussusception is $80 \%$, and the rest may occur in ileoileal or colocoic. Most infants and toddlers have no specific early condition that can be identified. $^{4}$

In Indonesia, intestinal obstruction was recorded in several areas such as Cirebon which occurred in 2006 and placed sixth out of ten highest causes of mortality in children aged 1 to 4 years old with 3 out of 88 cases. The data also showed that other areas such as Medan, specifically in dr. Pringadi General Hospital in 2007-2010, revealed $11.5 \%$ intestinal obstruction cases out of 111 cases. $^{5}$

Possibility of complication still exists in ileostomy procedure, from mild to life-threatening. By understanding early signs of the disease, with proper diagnosis and treatment, it is expected that the mortality rate of patients could be reduced. ${ }^{6}$ This study aimed to determine the description of pediatric patients who underwent ileostomy in Dr. Soetomo General Hospital Surabaya.

\section{Methods}

This study was a cross-sectional study with retrospective descriptive method that used medical records data from Pediatrics and General Surgery Inpatient
Installation of Dr. Soetomo General Hospital Surabaya from January 2017 to December 2018. This study was conducted from December 2018 to May 2019. The population in this study was all pediatric patients with ileum stoma treatment from 2017-2018 in Department of Pediatrics and General Surgery Inpatient Installation of Dr. Soetomo General Hospital Surabaya. All pediatric patients who received ileum stoma treatment that were admitted in Department of Pediatrics and General Surgery Inpatient Installation of Dr. Soetomo General Hospital Surabaya from 2017-2018 with complete medical record were included in this study, thus there were 26 samples obtained. The variables in this study include age, gender, preoperative weight, nutritional status, surgery indication, surgery history, and outcome. The data used were secondary data from Department of Pediatrics and General Surgery Inpatient Installation of Dr. Soetomo General Hospital Surabaya in the form of medical records with patients who underwent ileostomy in Dr. Soetomo General Hospital Surabaya. The inclusion criteria were all pediatric patients receiving treatment for stile ileum in Department of Pediatrics and General Surgery Inpatient Installation of Dr. Soetomo General Hospital Surabaya from January 2017 to December 2018 with a complete medical record including the variables previously mentioned. The exclusion criteria were those sample with incomplete medical record.

The sampling procedure that was used in this research was total sampling, meaning all data that met the inclusion and exclusion criteria were included. The data was analyzed descriptively using Microsoft Excel 2013. Editing, coding, entry, and cleaning were performed on collected data. Afterwards, the data were divided according to variables and are presented in frequency distribution table, cross table, or graph.

\section{Results}

The followings are the characteristics of the study population based on a sample of pediatric patients who performed an ileostomy with predetermined variables consisting of the patient's age at the surgery, preoperative body weight, gender, indication of surgery, history of surgery, outcome, and nutritional status of the patient.

Table 1. Distribution of pediatric patients with ileum stoma according to age, preoperative weight, and gender.

\begin{tabular}{lcc}
\hline & $\mathbf{N}$ & Percentage (\%) \\
\hline Operative Age & & \\
Neonates (0-28 days) & 15 & $57.7 \%$ \\
Infants (1-12 months) & 8 & $30.8 \%$ \\
Toddlers (1-5 years old) & 3 & $11.5 \%$ \\
Total & $\mathbf{2 6}$ & $\mathbf{1 0 0 \%}$ \\
\hline \multicolumn{2}{|l}{ Weight (kg) } & \\
$\quad 2.0-2.9$ & 8 & \\
$3.0-3.9$ & 7 & $30.7 \%$ \\
$>4.0$ & 11 & $27 \%$ \\
Total & $\mathbf{2 6}$ & $42.3 \%$ \\
\hline
\end{tabular}




\section{Gender}

Male $\quad 15-57.7 \%$

Total

Female

11

26

$42.3 \%$

$100 \%$

The results showed that the most frequent age was neonates with 15 patients (57.7\%), followed by infants with 8 patients $(30.8 \%)$, and the least was toddlers with 3 patients (11.5\%). The most frequently found weight category was more than $4 \mathrm{~kg}$ with 11 patients $(42.3 \%)$, followed by $2.0-2.9 \mathrm{~kg}$ with 8 patients $(30.7 \%)$, and $3.0-3.9$ $\mathrm{kg}$ with 7 patients $(2.7 \%)$. According to the gender, it showed that the majority of the samples was male with 15 patients $(57.7 \%)$, while female patients were 11 patients $(42.3 \%)$.

Table 2. Distribution of pediatric patients with ileum stoma according to indication, history of surgery, and outcome.

\begin{tabular}{lcc}
\hline & $\mathbf{N}$ & Percentage (\%) \\
\hline Indication of Surgery & & \\
Intestinal atresia & 9 & $34.6 \%$ \\
Intussusception & 8 & $30.8 \%$ \\
Hirschsprung's disease & 5 & $19.2 \%$ \\
Others & 4 & $15.4 \%$ \\
Total & $\mathbf{2 6}$ & $\mathbf{1 0 0 \%}$ \\
\hline & & \\
History of Surgery & & \\
Yes & 9 & $34.6 \%$ \\
No & 17 & $65.4 \%$ \\
Total & $\mathbf{2 6}$ & $\mathbf{1 0 0 \%}$ \\
\hline & & \\
Outcome & & \\
Completely healed & 4 & $15.4 \%$ \\
Periodic follow-up & 15 & $57.7 \%$ \\
Forced discharged & 1 & $3.8 \%$ \\
Died & 6 & $23.1 \%$ \\
Total & $\mathbf{2 6}$ & $\mathbf{1 0 0 \%}$ \\
\hline
\end{tabular}

The patients who had intestinal atresia and underwent ileostomy were 9 patients $(34.6 \%)$, followed by intussusception with 8 patients $(30.8 \%)$, Hirschsprung's disease with 5 patients (19.2\%), and other causes with 4 patients (15.4\%). According to the surgical history, the majority of the samples had no history of surgery (17; $65.4 \%$ ), while patients who had history of surgery were 9 patients $(34.6 \%)$. The outcome showed that the patients who underwent ileostomy were mostly discharged with periodic follow-up (15 patients; $57.7 \%$ ), followed by died with 6 patients $(23.1 \%)$, completely healed with 4 patients $(15.4 \%)$, and only 1 patient was forced discharged (3.8\%).

Table 3. Distribution of pediatric patients with ileum stoma according to nutritional status.

\begin{tabular}{lll}
\hline & $\mathbf{N}$ & Percentage (\%) \\
\hline Nutritional Status & & \\
Under-nourished & 1 & $3.8 \%$ \\
Well-nourished & 24 & $92.4 \%$ \\
Over-nourished & 1 & $3.8 \%$ \\
Total & $\mathbf{2 6}$ & $\mathbf{1 0 0 \%}$ \\
\hline
\end{tabular}

The nutrition status showed that the most frequent nutritional status was well-nourished with 24 patients $(92.4 \%)$, and poor-nourished and over-nourished were each consisted of 1 patient (3.8\%).

\section{Discussion}

The results of the study revealed that the most frequently found patients with ileostomy were aged 0-28 days old. This is due to the highest intestinal obstruction incidence occurred in infants aged less than 1 year old. ${ }^{7}$

According to a literature, the estimated incidence was 1 out of 1,500 living birth and intestinal atresia is the most common cause of intestinal obstruction. ${ }^{8}$ Obstructive symptoms usually occur within the first month of live with $50 \%$ incidence and increases to $90 \%$ within the first year. ${ }^{9}$

The majority of pediatric patients with ileum stoma did not have problems on their weight and should have normal body mass index (BMI) result. A study in 2012 showed that out of 130 patients, 108 (72.0\%) patients maintained their BMI level during observation period. Meanwhile, 22 (14.7\%) patients experienced decreasing BMI level. ${ }^{10}$

There were also underweight ileum stoma patients. This might happen due to premature birth. When ileostomy was performed, the average age was 18 days (ranging from 3-99 days) with the average weight of 887 gram (ranging from 510-1480 gram). The average duration of ileostomy surgery was 49 minutes (ranging from 36-74). During early postoperative period, one neonate with spontaneous intestinal perforation (SIP) died because of fatal liver hemorrhage after a few hours of ileostomy. Two other patients died due to prematurity disease that occurred before stoma reversal. ${ }^{11}$

lleostomy is mostly performed in male children compared to female ones due to higher intussusception risk factor. ${ }^{12}$ The results of this study are similar to the results of a study from Presidente Dutra University Hospital (HUPD), Brazil in 2016 with 110 pediatric patients which consisted of $86(78.2 \%)$ males and 24 (21.8\%) females. ${ }^{13}$ In 2011, Nigeria investigated 27 (61.4\%) male patients and $17(38.6 \%)$ female patients. ${ }^{14}$

The indication for most surgery was intestinal atresia with 9 (34.6\%) patients, followed by intussusception with 8 (30.8\%) patients, Hirschsprung's disease with 5 (19.2\%) patients, and other disease with 4 (15.4\%) patients. According to literature, intestinal atresia is the most common cause of ileostomy in children. Intestinal atresia, especially in jejunoileal, occurs in 1 out of 5,000 living birth that affected male and female equally. In several cases, Hirschsprung's disease, malrotation, and other disorders related to jejunoileal atresia were also found, albeit rare. ${ }^{15}$ Intraoperative biopsy on terminal ileum and colon can confirm Hirschsprung's disease in newborns, thus ileostomy can be performed. ${ }^{16}$

According to their surgical history, out of 26 patients, $17(65.4 \%)$ patients did not have history of surgery, while the rest $9(34.6 \%)$ patients had a history of surgery. The former was due to congenital disorder since birth. Intestinal obstruction is a most common surgical emergency in newborn babies. ${ }^{17}$ One of the study in the United States showed that intestinal malrotation with midgut volvulus occurred in 1 out of 500 babies. Atresia and jejunoileal 
stenosis had a combined incidence of 1 out of $1,500-5,000$ living birth. ${ }^{18}$

According to the outcomes, most patients were discharged and underwent periodic follow-up with 15 (57.7\%) patients, followed by patients who died with 6 (23.1\%) patients, completely healed with 4 (15.4\%) patients, and forced discharged with 1 (3.8\%) patient. Mortality rate may reach $65 \%$ if more than $75 \%$ of small intestines underwent necrosis. ${ }^{19}$ The mortality and morbidity of pediatric patients with small intestinal obstruction depends on the type of lesion that causes intestinal blockage, either closed loop or strangulated obstruction.

Mortality rate can be suppressed with early diagnosis and treatment. Without treatment, the blockage may be lifethreatening. Too much intestinal damage can cause malnutrition which then lead to short bowel syndrome..$^{20}$ From January 2017 to December 2018 showed that there were $83(67.5 \%)$ patients in need for improvement, followed by completely healed with $29(23.6 \%)$ patients, then died with $6(4.9 \%)$ patients, and not healed or forced discharged after operative procedure with $5(4.1 \%)$ patients. ${ }^{21}$

However, the nutritional status of children with ileum stoma was mostly well-nourished with 24 (92.4\%) patients and 1 patient $(3.8 \%)$ for under-nourished and overnourished. Similar study stated that early nutritional assessment found that the percentage of malnourished patients varied with different parameters of nutritional assessment. 7 (12.06\%) patients had BMl $<18.5$ and under-nourished, 49 (84.48\%) patients had normal BMI, and only 2 patients (3.44\%) were overweight. ${ }^{22}$ Stoma should not essentially cause serious malnutrition, real weight loss such as BMI level decrease can be correlated with the possibility of postoperative complication. ${ }^{23}$

\section{Conclusion}

According to the results of the study and data analysis, it can be concluded that the outcome of pediatric patients with ileum stoma in Dr. Soetomo General Hospital Surabaya revealed conditions that still require periodic improvement or postoperative follow-up, however the nutritional status of the majority of the patients was good during ileostomy. The number of cases of children with ileum stoma in Dr. Soetomo General Hospital Surabaya in 2017-2018 revealed 26 patients with the average age of newborn, normal weight and normal BMI, and the highest incidence occurred in male patients. The most frequent cause of ileostomy in children was intestinal atresia which is one of the congenital disorder of newborns. Therefore, a more thorough study is needed in expectation of larger sample size and more specific inclusion criteria to obtain a more objective description.

\section{CONFLICT OF INTEREST}

The author stated there is no conflict of interest in this study.

\section{REFERENCES}

1. Murwani. Pedoman Kateterisasi Urin. Revised ed. Jakarta: EGC, 2009.

2. Chirdan LB, Uba AF and Pam SD. Intestinal Atresia: Management Problems in a Developing Country. Pediatric Surgery International. 2004; 20: 834-7.

3. Fulham J. Providing Dietary Advice for the Individual with a Stoma. British Journal of Nursing (Mark Allen Publishing). 2008; 17: S22-7.

4. Vestergaard M, Pedersen MG, Ostergaard JR, Pedersen $\mathrm{CB}$, Olsen $\mathrm{J}$ and Christensen $\mathrm{J}$. Death in children with Febrile Seizures: A Population-Based Cohort Study. Lancet (London, England). 2008; 372: 457-63.

5. Pasaribu N. Karakteristik Penderita lleus Obstruktif yang Dirawat Inap di RSU Dr. Pirngadi Medan Tahun 2007-2010. Fakultas Kesehatan Masyarakat. Medan: Universitas Sumatra Utara, 2012

6. Flynn-O'Brien KT, Rice-Townsend S and Ledbetter DJ. 71 - Structural Anomalies of the Gastrointestinal Tract. In: Gleason CA and Juul SE, (eds.). Avery's Diseases of the Newborn (Tenth Edition). Philadelphia: Elsevier, 2018, p. 1039-53.e3.

7. Khairpur N, Sindh P, Soomro F, Wagan Ms and Sultana R. On the Incidences of Oedipodinae (Orthoptera: Acrididae) from. 2014; 5: 2222-3045.

8. Springer SC. Intestinal Obstruction in the Newborn: Background, Anatomy, Pathophysiology, Etiology, Epidemiology, Prognosis: (2013, accessed 28 May 2019). 9. Shiau S-Y, Yu H-L, Hwa S, Chen S-Y and Hsu S-I. The Influence of Carboxymethylcellulose on Growth, Digestion, Gastric Emptying Time and Body Composition of Tilapia. Aquaculture. 1988; 70: 345-54.

10. Kim MS, Kim HK, Kim DY and Ju JK. The Influence of Nutritional Assessment on the Outcome of Ostomy Takedown. Journal of the Korean Society of Coloproctology. 2012; 28: 145-51.

11. Kelsen JR. Ulcerative Colitis in Children: Background, Epidemiology, Prognosis, Patient Education: (2019, accessed 27 June 2018).

12. Lennard-Jones JE and Shivananda S. Clinical Uniformity of Inflammatory Bowel Disease a Presentation and during the First Year of Disease in the North and South of Europe. EC-IBD Study Group. European Journal of Gastroenterology \& Hepatology. 1997; 9: 353-9.

13. dos Santos OJ, Sauaia Filho EN, Barros Filho AKD, et al. Children and Adolescents Ostomized in a Reference Hospital. Epidemiological Profile. Journal of Coloproctology (Rio de Janeiro). 2016; 36: 75-9.

14. Anyanwu LJ, Mohammad A and Oyebanji T. A Descriptive Study of Commonly Used Postoperative Approaches to Pediatric Stoma Care in a Developing Country. Ostomy/Wound Management. 2013; 59: 32-7.

15. Sweeney B, Surana R and Puri P. Jejunoileal Atresia and Associated Malformations: Correlation with the Timing of in Utero Insult. Journal of Pediatric Surgery. 2001; 36: 774-6.

16. Daher W, Klages N, Carlier MF and Soldati-Favre D. Molecular Characterization of Toxoplasma gondii Formin 3, 
An Actin Nucleator Dispensable for Tachyzoite Growth and Motility. Eukaryotic Cell. 2012; 11: 343-52.

17. Baker ML, Williams RN and Nightingale JM. Causes and Management of a High-Output Stoma. Colorectal Disease : The Official Journal of the Association of Coloproctology of Great Britain and Ireland. 2011; 13: 191-

18. Burch J. The Management and Care of People with Stoma Complications. British Journal of Nursing (Mark Allen Publishing). 2004; 13: 307-8, 10, 12, 14-8.

19. Colwell JC and Fichera A. Care of the Obese Patient with an Ostomy. Journal of Wound, Ostomy, and Continence Nursing : Official Publication of The Wound, Ostomy and Continence Nurses Society. 2005; 32: 378-83; quiz 84-5.
20. Adams M and Moss M. Food Microbiology. 2nd ed. Cambridge: The Royal Society of Chemistry, 2007.

21. Sari N, Ismar I and Nazriati E. Gambaran lleus Obstruktif pada Anak di RSUD Arifin Achmad Provinsi Riau Periode Januari 2012-Desember 2014. Riau University, 2015.

22. Mohil RS, Narayan N, Sreenivas S, Singh N, Bansal A and Singh GJ. Challenges of Managing Emergency lleostomy: Nutrition-A Neglected Aspect. ISRN Emergency Medicine. 2012; 2012: 968023.

23. Dalla Vecchia LK, Grosfeld JL, West KW, Rescorla FJ, Scherer LR and Engum SA. Intestinal atresia and stenosis: a 25-year experience with 277 cases. Archives of surgery (Chicago, III : 1960). 1998; 133: 490-6; discussion 6-7. 